See Article page 382 .

\section{Commentary: We are in the same minimally invasive boat, and we have to row in the same direction}

\author{
Luca Bertolaccini, $\mathrm{MD}, \mathrm{PhD},{ }^{\mathrm{a}}$ and \\ Lorenzo Spaggiari, $\mathrm{MD}, \mathrm{PhD}^{\mathrm{a}, \mathrm{b}}$
}

Despite the superiority of robotic-assisted thoracic surgery (RATS) over video-assisted thoracic surgery (VATS) for mediastinal masses, in this issue of the Journal, Alushani and colleagues ${ }^{1}$ confirm the broad availability of VATS in most of the developing world, owing to the higher costs and inconsistent accessibility of RATS.

Since the 1990s, the awareness of minimally invasive surgery has grown extensively, thanks to its remarkable benefits compared with thoracotomy. ${ }^{2}$ Several studies have verified that minimally invasive approaches are not inferior to thoracotomy in terms of oncologic outcomes. The advantages of RATS in dexterity and depth of visualization delivered facilitates execution of more complicated procedures and increases the visual strain for surgeons. ${ }^{3}$ Like the debate stimulated by the introduction of VATS, RATS also needed to address challenges, such as cost-effectiveness. ${ }^{4}$ Despite comprehensive cost analysis reviews, there are no prospective cost comparisons or cost-effectiveness analyses. The higher costs of RATS were demonstrated in systematic reviews and meta-analyses. Nevertheless, quality and rigor are challenged by the retrospective nature and limited sample size of included studies. ${ }^{5}$ Most of them included heterogeneous patients in terms of disease stage and comorbidity and did not use propensity matching. ${ }^{6}$ Therefore, conclusions regarding the cost-effectiveness are not possible in

From the a Department of Thoracic Surgery, IEO, European Institute of Oncology IRCCS, Milan; and ${ }^{\mathrm{b}}$ Department of Oncology and Hemato-Oncology, University of Milan, Milan, Italy.

Disclosures: The authors reported no conflicts of interest.

The Journal policy requires editors and reviewers to disclose conflicts of interest and to decline handling or reviewing manuscripts for which they may have a conflict of interest. The editors and reviewers of this article have no conflicts of interest.

This work was partially supported by the Italian Ministry of Health with Ricerca Corrente and $5 \times 1000$ funds.

Received for publication Aug 10, 2020; revisions received Aug 10, 2020; accepted for publication Aug 13, 2020; available ahead of print Aug 15, 2020.

Address for reprints: Luca Bertolaccini, MD, PhD, Division of Thoracic Surgery, IEO, European Institute of Oncology, IRCCS, via Ripamonti 435, 20141 Milan,

Italy (E-mail: luca.bertolaccini@gmail.com).

JTCVS Techniques 2020;4:387-8

2666-2507

Copyright (C) 2020 The Authors. Published by Elsevier Inc. on behalf of The American Association for Thoracic Surgery. This is an open access article under the CC BY-NCND license (http://creativecommons.org/licenses/by-nc-nd/4.0/).

https://doi.org/10.1016/j.xjtc.2020.08.035

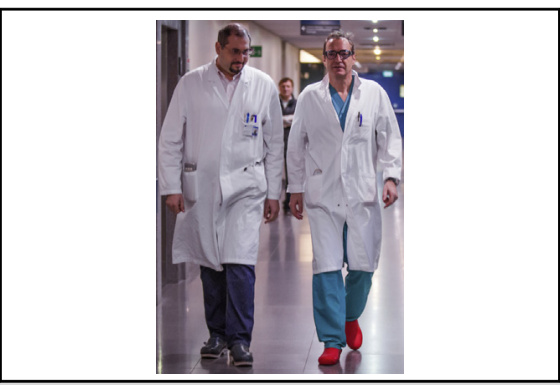

Luca Bertolaccini, MD, PhD (left), and Lorenzo Spaggiari, MD, PhD (right)

CENTRAL MESSAGE

Conclusions regarding the costeffectiveness of robotic surgery are not possible without prospective long-term data. Even assuming that costs represent a real issue, they will decrease with technological advancements.

the absence of prospective long-term data. ${ }^{5}$ Even if the cost of RATS (especially in a time of increasing healthcare expenditures) is a real issue, the device-related costs will decrease with advances in the technologies. ${ }^{3}$

Rather than discuss the costs of each approach against the others, we should discuss oncologic efficacy across the minimally invasive approaches and then highlight nononcologic outcomes. Intuitively, everyone would support minimally invasive surgery, via VATS or RATS, if it were able to offer the required decrease in morbidity and at least comparable (if not enhanced) oncologic outcomes. Ideal statistical comparisons of minimally invasive approaches and thoracotomy in terms of cost will continue to be challenging. The result is a time of vagueness when minimally invasive approaches could take root in practice and allows a chance for innovation in standards of care. ${ }^{7}$

Therefore, minimally invasive surgeons should row in the same direction-but which direction precisely? The bright and consistent communication between VATS and RATS surgeons will be crucial; otherwise, technological improvements and cost reductions will be left in the dark. So minimally invasive teams should keep in the loop toward the development of a unique, more reliable, and dynamic minimally invasive team. Imagine what patients could achieve if minimally invasive surgeons could work together in their areas of giftedness, regularly and over a long period, all 
rowing in the same direction. As one opportunity leads to another, before you know it, RATS and VATS surgeons will look up and say "mission accomplished."

We thank Dr Elena Prisciandaro for proofreading the manuscript.

\section{References}

1. Alushani D, HE, Bizhga M, Saraci B, Khen-Dunlop N. Thoracoscopic resection of esophageal duplication causing tracheobronchomalacia in a 5-year-old patient. J Thorac Cardiovasc Surg Tech. 2020;4:382-5.

2. Ricciardi S, Davini F, Zirafa CC, Melfi F. From "open" to robotic assisted thoracic surgery: why RATS and not VATS? J Vis Surg. 2018;4:107.
3. Guo F, Ma D, Li S. Compare the prognosis of Da Vinci robot-assisted thoracic surgery (RATS) with video-assisted thoracic surgery (VATS) for non-small cell lung cancer: a meta-analysis. Medicine (Baltimore). 2019; 98:e 17089

4. Nakazawa S, Shimizu K, Mogi A, Kuwano H. VATS segmentectomy: past, present, and future. Gen Thorac Cardiovasc Surg. 2018;66:81-90.

5. Agzarian J, Fahim C, Shargall Y, Yasufuku K, Waddell TK, Hanna WC. The use of robotic-assisted thoracic surgery for lung resection: a comprehensive systematic review. Semin Thorac Cardiovasc Surg. 2016;28:182-92.

6. Montagne F, Bottet B, Sarsam M, Mbadinga F, Chaari Z, Rinieri P, et al. Robotic versus open and video-assisted thoracoscopic surgery approaches for lobectomy. Mini-invasive Surg. 2020;4:17.

7. Upham TC, Onaitis MW. Video-assisted thoracoscopic surgery versus robotassisted thoracoscopic surgery versus thoracotomy for early-stage lung cancer. $J$ Thorac Cardiovasc Surg. 2018;156:365-8. 